Review

\title{
Thromboembolism in Patients with Hypertrophic Cardiomyopathy
}

\author{
Lu Liu, MD1, Zheng Liu, BS², Xiaoping Chen, $\mathrm{MD}^{1^{\bowtie}}$, and Sen He, MD, $\mathrm{PhD}^{1 凶}$ \\ 1. Department of Cardiology, West China Hospital of Sichuan University, Chengdu, China \\ 2. Nursing Department, West China School of Nursing, West China Hospital of Sichuan University, Chengdu, China \\ Lu Liu and Zheng Liu equally contribute to the article \\ $\square$ Corresponding authors: Xiaoping Chen and Sen He; Department of Cardiology, West China Hospital, Sichuan University No.37, Guo Xue Xiang, Chengdu, \\ Sichuan, 610041, China Tel: +86 028 85422343; Fax: +86 028 85422175; Email address: 2019224020015@stu.scu.edu.cn (for Xiaoping Chen), hesensubmit@163.com \\ (for Sen $\mathrm{He}$ ). \\ (c) The author(s). This is an open access article distributed under the terms of the Creative Commons Attribution License (https://creativecommons.org/licenses/by/4.0/). \\ See http://ivyspring.com/terms for full terms and conditions.
}

Received: 2020.07.01; Accepted: 2020.11.18; Published: 2021.01.01

\begin{abstract}
Hypertrophic cardiomyopathy (HCM) is an inherited cardiac disease, which has a marked heterogeneity in clinical expression, natural history, and prognosis. HCM is associated with a high prevalence of thromboembolic events (stroke and systemic embolic events), even if taking no account of atrial fibrillation (AF), leading to unexpected disability and death in patients of all ages. Several risk factors of thromboembolism such as AF, greater age, left atrial diameter, heart failure and others have been confirmed in patients with HCM. Conventional thromboembolic predictive models were estimated by several trials in HCM population but it turned out to be unsatisfactory. Based on those previous explorations, researchers tried to modify or develop novel models suitable for HCM population in thromboembolism prediction. In consideration of catastrophic advent events of thromboembolism, current guidelines have recommended life-long anticoagulant therapy after a single short AF.

Therefore, early identification of risk factors for thromboembolism, accurate risk stratification, timely preventive measures and aggressive management may help to avoid serious adverse thromboembolic events in HCM population.
\end{abstract}

Key words: hypertrophic cardiomyopathy, thromboembolism, stroke, anticoagulant therapy, atrial fibrillation

\section{Introduction}

Hypertrophic cardiomyopathy (HCM) is characterized as hypertrophy of the left ventricle, usually asymmetric and involving interventricular septum[1, 2]. Myocyte hypertrophy and disarray as well as interstitial fibrosis are also the key pathological hallmarks. Moreover, impaired ventricular filling and dynamic left ventricular outflow tract (LVOT) obstruction are important pathophysiologic features[3]. It has been confirmed that HCM is an inherited disease, an autosomal dominant inheritance is a typical model[4-6]. Over 450 mutations in 20 sarcomeric and myofilament-related proteins have been identified, involving $\beta$-myosin heavy chain, cardiac troponin $\mathrm{T}$, cardiac troponin $\mathrm{I}$, a-tropomyosin, cardiac myosin binding protein $\mathrm{C}$, the essential and regulatory myosin light chains, and cardiacactin[2, 7-10]. HCM is common with a prevalence of 1 in 500 and even up to 1 in 200[1, 11-15]. HCM is heterogeneous with a wide spectrum of clinical manifestations, including heart failure (HF), atrial and ventricular arrhythmias and sudden cardiac death, as well as thromboembolism[1, 11, 12].

Thromboembolism events, including stroke and systemic embolic events, known as profound complications of HCM, have a high incidence rate in HCM patients and often lead to catastrophic adverse events, which is consequently related to increased morbidity and mortality[16-20]. For HCM patients, the current issues are mostly concentrated on the risk stratification of sudden cardiac death or the therapeutic dilemma of alcohol septal ablation versus surgical myectomy[21]. However, the high incidence 
and the poor prognosis of thromboembolic events in this population should not be ignored.

This review covers a series of issues concerning thromboembolic events in patients with HCM, with a focus on the epidemiology, risk factors, prediction models, and management.

\section{Epidemiology}

According to previous studies all over the world, both the prevalence and incidence of thromboembolism are high in patients with HCM, especially in patients with atrial fibrillation $(\mathrm{AF})[12$, $13,15,22,23]$. In Asia, based on the data on patients diagnosed with HCM from the entire Korean population between 2005 and 2015, the prevalence of stroke was approximately 10\%[24]. Similarly, in a regional Japanese cohort, the 5-year embolic event rate was 5.5\%[25]. In Europe, a retrospective, longitudinal cohort of seven institutions, having excluded patients with a history of AF and thromboembolic events prior to the first evaluation, recruited $4821 \mathrm{HCM}$ patients and demonstrated that $172(3.6 \%)$ patients reached the primary endpoint within 10 years, including 105 cerebrovascular accidents (CVA), 53 transient ischaemic attacks (TIA) and 14 peripheral emboli, and the 5- and 10-year cumulative incidences were $2.9 \%$ and $6.4 \%$ (95\% CI $2.37-3.48 \%$ vs. $5.42-7.53 \%$, respectively)[26].

The patients with HCM who have suffered thromboembolism have a poor prognosis. In a prospective trial, 900 patients with HCM were consecutively enrolled and prospectively followed between 1970 and 1998, and 51 (6\%) patients suffered stroke or other vascular events over $7 \pm 7$ years, finally, $21(41 \%)$ of these 51 patients died or were permanently disabled[20]. Recently, Lorenzini et al. reported that compared with the general population, adult patients with HCM had excess mortality in a large international multicenter referral cohort[27].

\section{Risk Factors of Thromboembolism in HCM}

\section{Atrial fibrillation}

Atrial fibrillation (AF), determined by electrocardiogram, Holter monitoring, or medical history, is the most common sustained arrhythmia in $\mathrm{HCM}$ and has a prevalence of $20 \%-25 \%$ in HCM patients, which is 4-6 fold higher likelihood than that in the general population[13, 28-31]. The prevalence and annual incidence of thromboembolism events were $27.1 \%$ and $3.8 \%$ respectively in HCM patients with $\mathrm{AF}[13,32]$. In a study based on the entire Korean population between 2005 and 2015[24], the prevalence of stroke in HCM patients with AF was $20 \%$, double of that in the whole HCM patients. The authors also stated that during 8741 person-years, AF-related stroke occurred in 257 subjects among 2309 HCM patients with new-onset $\mathrm{AF}$, and the overall incidence rate of AF-associated stroke was 2.94 per 100 person-years. In HCM patients, the incidence of ischaemic strokes was 8 times higher in patients with AF than in those with sinus rhythm[33]. This obvious discrepancy about thromboembolic events might be attributed to anti-cardiolipin antibody (aCLa), produced by some cell line in the HCM heart when AF occurs; another speculative possibility is that thrombogenesis of the endothelium in HCM hearts is enhanced by LVOT obstruction, though no assessment of this possibility is yet available[34]. HCM patients more commonly develop AF at a younger age in comparison with the general population[35]. AF is poorly tolerated by HCM populations, largely owing to their left ventricular filling dependent on atrial systole[13, 33]. The association between $\mathrm{AF}$ and high risk of thromboembolism in HCM patients has been confirmed[36-38].

AF tends to be paroxysmal in two-thirds of HCM patients and persistent/permanent in the remaining one-third[33]. The definitions of different types of AF varied between studies[13]. Persistent AF was found in $50 \%$ of patients having thromboembolism[18], while paroxysmal AF was reported in 11 out of 18 in the thromboembolic patients[39]. However, the incidence of thromboembolism between HCM patients with paroxysmal AF and those with chronic AF was reported not significantly different[33, 40], and the thromboembolism risk in AF is not related to the number of paroxysms as well[41].

\section{Left atrial diameter}

Left atrial diameter (LAD) has also been verified to be a risk factor for thromboembolism, associated with the development of AF as well[42]. However, it has been found that the enlargement of the left atrial tended to be greater in the embolism group than that in those with AF but without systemic embolism[43]. In patients with $\mathrm{HCM}$ without $\mathrm{AF}$, Haruki et al.[22] have suggested that each $1 \mathrm{mmm}$ increase in LAD prefigures the increased risk of stroke-related death (HR 1.10, 95\% CI 1.00-1.20). As for the relationship between left atrial size and risk of thromboembolic events, there seems to be a linear relationship, and the risk of thromboembolism rises exponentially with increasing LAD up to $45-50 \mathrm{~mm}[26]$.

\section{Greater age}

Greater age is also a significant risk factor acknowledged by a host of trials[20, 22, 26, 44]. 
Guttmann et al.[26] developed exploratory multivariable analysis and revealed age as a predictor of thromboembolism in HCM (HR 1.03, 95\% CI 1.021.04, $\mathrm{p}<0.001)$. Maron et al.[20] stratified age and regarded age as independent $(\mathrm{p}<0.00)$. Moreover, the older the HCM patients were, the higher risks of thromboembolism they were faced with (RR 1.6, $95 \%$ CI $0.8-3.6$ vs. RR $8.2,95 \%$ CI 3.9-21.6 for $41-60$ and $>60$ years old, respectively).

\section{Heart failure}

Heart failure (HF), characterized by excessive exertional dyspnea, is a common complication with a broad illness states, from mild to severe (New York Heart Association [NYHA] functional classes II-IV) in $\mathrm{HCM}[45,46]$. In a prospectively followed-up of an HCM group[20] , 51 patients experienced one or more cerebrovascular or other peripheral vascular events. And at the time of the initial event, 19 patients (37\%) had severe symptoms (NYHA functional class III or IV), including 7 patients in the end-stage phase with systolic ventricular dysfunction. In a recent newly developed model predicting thromboembolic events for HCM patients, Cox regression revealed an association between thromboembolism and NYHA class, and the authors regarded congestive heart failure symptoms and NYHA functional class as risk factors[26].

\section{Other risk factors}

Late gadolinium enhanced (LGE) extent $>14.4 \%$ on cardiovascular magnetic resonance (CMR) was regarded as an independent predictor for thromboembolic events in HCM patients (sensitivity $65 \%$, specificity 78.1\%, AUC 0.79, P<0.0001)[47]. A study reported $\mathrm{CHADS}_{2}>1$ combined with left ventricular outflow tract gradient (LVOTG) $>38$ $\mathrm{mmHg}$ was an independent predictor of embolic stroke in HCM patients[48]. Additionally, some factors associated with AF like left ventricular outflow tract obstruction, systolic anterior movement (SAM), mitral regurgitation (MR)[49]predisposing hemodynamic might increase the thromboembolic risk. Others such as prior thromboembolism, maximal wall thickness, vascular diseases, and hyperuricemia have been put forward as risk factors on thromboembolism in HCM patients in some researches[20, 26, 50], but the data is limited and further estimations are required.

According to the prior researches, several simple and common clinical features can be used to identify the risks of thromboembolism in HCM patients, which are concluded in Table 1.

\section{Thromboembolism Predictive Models}

Regardless of the proposal of risk factors for thromboembolism, comprehensive risk stratification of thromboembolism in patients with HCM still challenges the clinical decision making and is urgent to be solved.

Table 1. Risk Factors of Thromboembolism in patients with Hypertrophic Cardiomyopathy

\begin{tabular}{|c|c|c|c|c|}
\hline Risk Factor & Citation & $P$ value & Strength & $95 \% \mathrm{CI}$ \\
\hline \multirow[t]{6}{*}{ Greater age } & Guttmann et al. [26] & $<0.001$ & HR 1.03 & $1.02-1.04$ \\
\hline & Haruki et al. [22] & 0.012 & HR 1.03 & $1.01-1.06$ \\
\hline & Maron et al. [20] & $<0.005$ & RR $1.6^{a}$ & $0.8-3.6^{\text {a }}$ \\
\hline & & & $\mathrm{RR} 8.2^{\mathrm{b}}$ & $3.9-21.6^{b}$ \\
\hline & Lin et al. [44] & $<0.05$ & HR $1.278^{c}$ & $1.070-1.335^{c}$ \\
\hline & & & HR $1.757 \mathrm{~d}$ & $1.435-2.152^{\mathrm{d}}$ \\
\hline \multirow[t]{4}{*}{$\mathrm{AF}$} & Guttmann et al.[26] & $<0.001$ & HR 8.41 & $1.95-36.3$ \\
\hline & Higashikawa et al.[19] & 0.0001 & RR 9.330 & $1.902-28.264$ \\
\hline & Maron et al.[20] & $<0.0001$ & RR 10.2 & $4.6-25.0$ \\
\hline & Tian et al.[36] & 0.03 & HR 6.71 & $1.23-38.58$ \\
\hline \multirow[t]{3}{*}{ LAD } & Haruki et al.[22] & 0.016 & HR 2.74 & $1.20-6.23$ \\
\hline & Guttmann et al.[26] & $<0.001$ & HR 1.03 & $1.01-1.05$ \\
\hline & Tian et al.[36] & 0.04 & HR 1.10 & $1.00-1.20$ \\
\hline \multirow[t]{2}{*}{ Prior TE } & Guttmann et al.[26] & $<0.001$ & HR 3.63 & $1.81-7.29$ \\
\hline & Wang et al.[50] & - & - & - \\
\hline \multirow[t]{2}{*}{ NYHA class III,IV } & Guttmann et al.[26] & $<0.001$ & HR 2.07 & $1.35-3.17$ \\
\hline & Maron et al.[20] & $<0.05$ & RR 2.4 & $1.2-5.0$ \\
\hline MWT & Guttmann et al.[26] & $<0.001$ & HR 1.45 & $1.12-1.88$ \\
\hline Vascular disease & Wang et al.[50] & - & - & - \\
\hline Hyperuricemia & Wang et al.[50] & 0.013 & HR 2.67 & $1.24-5.76$ \\
\hline LGE extent & Hohneck et al.[47] & $<0.0001$ & OR 1.1 & $1.05-1.16$ \\
\hline
\end{tabular}

LAD = left atrial diameter; LGE = late gadolinium enhancement on cardiovascular magnetic resonance; MWT = maximal wall thickness; NYHA = New York Heart Association; TE = thromboembolic event; -, not given; a, 41-60 years old; b, over 60 years old; c, 65-74 years old; d, over 75 years old. 


\section{HCM Risk-CVA}

Not long ago, to determine the risk of thromboembolism in patients with HCM, a novel risk model called HCM risk for cerebrovascular accident (HCM Risk-CVA) was developed[26]. The risk factors identified by this model, based on a retrospective, longitudinal cohort of seven institutions, include (1) age; (2) presence of AF; (3) previous thromboembolism: ischemic stroke, TIA and peripheral embolism; (4) NYHA classes II-IV; (5) presence of congestive heart failure symptoms; (6) vascular disease: myocardial infarction, complex aortic plaque, and peripheral arterial disease; (7) left atrial diameter and maximal ventricular wall thickness (MWT). HCM Risk-CVA showed prominent discrimination (C-statistic 0.75, 95\% CI 0.70-0.80; D-statistic 1.30, 95\% CI 1.05-1.56) and a good calibration slope of 0.91 (95\% CI 0.74-1.08) in the original study population.

The equation of the risk of thromboembolism in 5 years for an individual HCM patient is presented as following:

$$
\mathrm{p}=1-0.99998744^{\exp } \text { (prognostic index) }
$$

where the prognostic index $=0.030417476 \times$ age (years) $+2.129977874 \times \mathrm{AF}($ yes $=1 /$ no $=0)-$ $0.027069595 \times$ age $\times \mathrm{AF}+1.288557829 \times$ thromboembolic events prior (yes $=1 /$ no $=0)+$ $0.224673046 \times$ NYHA class II (yes $=1 /$ no $=0)+$ $0.728180341 \times \mathrm{NYHA}$ class III/IV (yes $=1 /$ no $=0)+$ $0.032251831 \times$ left atrial diameter $(\mathrm{mm})+0.3735254 \times$ maximal wall thickness $(\mathrm{mm})-0.008324216 \times$ maximal wall thickness ${ }^{2}(\mathrm{~mm})+0.512492795 \times$ vascular disease (yes $=1 /$ no $=0$ ).

Subsequently $\mathrm{He}$ et al.[51] carried out an external validation of this model in a relatively large cohort of patients with HCM, although their calibration was not perfect, HCM Risk-CVA could still help to discriminate the risk of thromboembolism in the whole cohort and the subgroup without AF.

Nevertheless, the complexity of HCM Risk-CVA limits its wide application more or less[52]. HCM Risk-CVA may be considered to guide risk management among the $\mathrm{HCM}$ population and prospective external validations of HCM Risk-CVA in different distributions and different ethnic cohorts become the urgent need.

\section{CHADS $_{2}$ and $\mathrm{CHA}_{2} \mathrm{DS}_{2}$-VASc}

To predicting the thromboembolic events in patients with $\mathrm{AF}$, the $\mathrm{CHADS}_{2}[53]$ and $\mathrm{CHA}_{2} \mathrm{DS}_{2}$-VASc[54] were developed, and the $\mathrm{CHA}_{2} \mathrm{DS}_{2}$-VASc score was previously used as a means of stratifying patients with non-valvular AF for thromboembolic events prophylaxis[55, 56].
However, in the HCM population, current guidelines issued by the European Society of Cardiology (ESC) or Japanese Circulation Society (JCS) do not recommend those traditional scoring systems in risk stratifying of thromboembolism[49, 57]. Several literature validating those models have also pointed out the defects not correlating well with the clinical outcomes in patients with HCM[24-26, 58-61]. In $\mathrm{HCM}$ individuals with $\mathrm{CHA}_{2} \mathrm{DS}_{2}$-VASc scoring 0 or 1 , the incidence rate of AF-associated stroke is 1.48 per 100 person-years[24]. According to a large-scale, longitudinal cohort study of HCM subjects in the absence of AF, those with CHA2DS2-VASc score $\leq 2$ had a significantly increased risk of ischemic stroke, compared with matched general population with AF (score 0, HR 2.062, 95\% CI $1.816-4.209, \mathrm{p}=0.026$; score 1, HR 2.261, 95\% CI $1.940-3.300, \mathrm{p}=0.018$; score 2, HR 1.383, 95\% CI $1.023-2.201, \mathrm{p}=0.034$ )[44].

\section{Other Models}

Tsuda et al.[61] incorporated HCM into $\mathrm{CHADS}_{2}$ score and $\mathrm{CHA}_{2} \mathrm{DS}_{2}$-VASc score, the modified risk models were superior to the customary scores alone for predicting thromboembolism $(\mathrm{P}=0.0033$ and $\mathrm{P}=0.0002$, respectively). Furthermore, ROC curves under the Cox model was constructed, and the C-statistics for prediction of thromboembolism showed 0.7120 (95\% CI 0.6675-0.7565), 0.7131 (95\% CI $0.6697-0.7565), 0.7561$ (95\% CI $0.7133-0.7989)$ and 0.7675 (95\% CI 0.7292-0.8059) for $\mathrm{CHADS}_{2}$ score, $\mathrm{CHA}_{2} \mathrm{DS}_{2}$-VASc score, $\mathrm{CHADS}_{2}$ score $+\mathrm{HCM}$ and $\mathrm{CHA}_{2} \mathrm{DS}_{2}$-VASc score + $\mathrm{HCM}$, respectively.

$\mathrm{R}-\mathrm{CHA}_{2} \mathrm{DS}_{2} \mathrm{VASc}$ score, which integrated GFR and BUN into $\mathrm{CHA}_{2} \mathrm{DS}_{2}$-VASc score and had been proved in good calibration and high discriminative performance predicting post-discharge ischemic stroke in a cohort of patients with a myocardial infarction before[62], indicated a satisfied result in stratifying thromboembolic risk and was well calibrated in patients with HCM as well[63].

\section{Thromboembolism Prophylaxis and Management}

\section{Anticoagulant Therapy}

Up to now, with $\mathrm{CHADS}_{2}$ and $\mathrm{CHA}_{2} \mathrm{DS}_{2}$-VASc not working well in the HCM population, there is no completely accordant scoring system available yet. In order to prevent thromboembolism as far as possible, ESC guidelines, ACCF/AHA guidelines, and several studies have strongly suggested the life-long oral anticoagulant therapy, warfarin therapy with goal international normalized ratio (INR) 2-3, in HCM patients with even a single brief episode of $\mathrm{AF}$, regardless of the conventional stroke-scoring systems, 
particularly given the high likelihood of recurrence of $\mathrm{AF}$ and risk of thromboembolism. And the treatment should be ongoing even if sinus rhythm is restored[33, $49,59,60,64,65]$.

In the absence of $\mathrm{AF}$, thrombosis could be promoted as well, due to the abnormal atrial substrate[66]. Similarly, in HCM patients without documented AF, abnormal atrial substrate and function could increase the risk of thromboembolism once AF occurs. Based on previous studies, the overall burden of stroke in HCM was variable and not specified with $\mathrm{AF}[18,19]$. In a study enrolling 593 patients with clinically diagnosed HCM from 1980 to 2010[22], the incidence of stroke and systemic embolic events was about $1.0 \%$ per year, and among the patients with events, however, there were more than half having not been documented AF before the embolic events. They also concluded that in patients with HCM without documented AF, older age and enlarged left atrial were possible risk factors for embolic events. Lin et al.[44] identified 17371 HCM patients without AF and utilized propensity-score-matching to identify one-to-one matched control of the general population with AF receiving oral anticoagulants. During a median follow-up of 7.3 years, 847 (4.9\%) subjects experienced ischemic stroke with the incidence of $0.589 / 100$ person-years, and the corresponding matched controls experienced $788(4.5 \%)$ events with the incidence of $0.494 / 100$ person-years. Compared with control, the HCM group without AF had a similar risk of ischemic stroke (HRs 0.965, 95\% CI 0.854-1.091), which implied that oral anticoagulants might be necessary for HCM patient even without AF. Stated thus, in terms of those HCM patients in the absence of AF but actually at thromboembolic risk (the older, LAD $\geq 48 \mathrm{~mm}$, LGE $>14.4 \%$ or others), prophylactic anticoagulant therapy might help prevent further thromboembolic events. At present, in clinical management, whether to apply prophylactic anticoagulant therapy remains to be ambiguous and urgent to be determined[22, 44, 47, 60,67].

Compared with those receiving warfarin, the cumulative incidence of stroke among patients with AF was significantly higher in the non-anticoagulant group $(18 \%$ vs. $31 \%, \mathrm{p}<0.05)$ in a consecutively enrolled and prospectively followed group of 900 HCM patients[20]. Another research also reported that embolic events were less common in patients taking anticoagulants $(4 / 233,2 \%)$ than in patients without anticoagulant prophylaxis $(9 / 66,14 \%$, $\mathrm{P}<0.001$ )[39].

Yet undertreatment in anticoagulation therapy exists. Real-world data from the GARFIELD-AF registry showed that the frequency of oral anticoagulants was less and target INR was lower in Asia than those in other regions of the world[68]. The actual use of oral anticoagulants in non-valvular atrial fibrillation (NVAF) patients with HCM was suboptimal that only $15.3 \%$ at the time of $\mathrm{AF}$ diagnosis and $61.8 \%$ throughout the study period received oral anticoagulants[37]. The situation in Europe is not optimistic as well that there are greater than one-third of patients with AF and known risk factors who should have received anticoagulation therapy not adhering to the prescription[69].

New oral anticoagulants (NOACs) might be reasonable alternatives to vitamin $\mathrm{K}$ antagonists (VKAs), but there is a paucity of data to support their application in patients with HCM and AF [70]. On the basis of current guidelines on HCM, if adjusted-dose VKAs fails to reach anticoagulant aims or if patients experience side effects of VKAs or are unable to undertake INR monitoring, a direct thrombin inhibitor (dabigatran) or an oral factor $X_{a}$ inhibitor (e.g. rivaroxaban, apixaban) is recommended[49, 71]. From a system review, the use of NOACs was associated with a lower pooled incidence rate of thromboembolic events at $4.7 \%$ compared to $8.7 \%$ with VKAs, as well as a lower pooled incidence rate of major bleeding and all-cause mortality in the NOACs group[72]. A nationwide cohort study from the Korean National Health Insurance Service database reported that, in consideration of all-cause mortality (5.11 vs. 10.13 events per 100 person-years, respectively) and the composite of fatal cardiovascular events (0.77 vs.1.80 events per 100 person-years, respectively), NOACs are superior to warfarin[73]. The results mentioned above are generally consistent with those from other researches[74, 75]. Furthermore, a recent study found that NOACs are at least as safe and effective as VKAs in patients with HCM undergoing catheter ablation for AF[76]. Whereas, the safety and efficacy of NOACs in the HCM population needs to be investigated in large and prospective randomized controlled trials in the future. For paroxysmal or chronic $\mathrm{AF}$, anticoagulation with vitamin $\mathrm{K}$ antagonist warfarin is recommended, although NOACs are available (eg, dabigatran or rivaroxaban)[77].

\section{Antiplatelet Treatment}

Besides the coagulation system, platelets can also be activated in patients with HCM[78, 79]. A study investigated the mean platelet volume (MPV), an indicator of platelet activation, and the result showed that the MPV could be elevated in patients with HCM[80].

In contrast, a meta-analysis including 4052 
patients with general AF from six randomized clinical trials showed that compared with aspirin, oral anticoagulants significantly reduced the likeliness to experience any stroke ( 2.4 vs. 4.5 events per 100 patient-years, HR $0.55,95 \%$ CI $0.43-0.71)$, ischemic stroke (HR 0.48, 95\% CI 0.37-0.63), or cardiovascular events (HR 0.71, 95\% CI 0.59-0.85)[81]. Actually, some substantial evidence bases are in favor of anticoagulation therapy other than antiplatelet treatment in the respects of curative efficacy, safety, and side effects [82-84].

Thus, antiplatelet therapy using aspirin 75$100 \mathrm{mg}$ plus clopidogrel $75 \mathrm{mg}$ daily should be only considered when patients refuse the use of any oral anticoagulants (whether VKAs or NOACs)[49].

\section{Other managements}

Unless AF is recognized timely, the consequence frequently is left atrial thrombosis and embolization, leading to stroke[34]. Timely identification of asymptomatic AF means early anticoagulant therapy. An asymptomatic paroxysmal episode or a first paroxysmal episode of AF in patients without previously documented AF may lead to thromboembolism[85-88]. Clinically asymptomatic $\mathrm{AF}$ appears to be common in HCM, occurring in almost $25 \%$ of patients[89, 90]. The American guidelines recommend that monitoring via 24-hour ambulatory electrocardiogram for asymptomatic AF should be considered in subjects with HCM[71]. While the European guidelines seem to be more cautious that HCM patients who are in sinus rhythm, but with a left atrial anterior-posterior diameter $\geq$ $45 \mathrm{~mm}$ should be monitored every 6 to 12 months via 48-hour ambulatory electrocardiogram[49]. Thus, HCM patients with otherwise considered cryptogenic stroke should be carefully monitored for AF since it was reported that $7.4 \%$ of them had new-onset $\mathrm{AF}$ at the time of thromboembolic events and 14.7\% developed AF during evaluation after stroke[22]. Implantable loop recorders could be taken into consideration if it is necessary[87].

Even though the development of AF in HCM patients may lead to poor clinical outcomes, there are no data specifically in HCM defining the relative benefits of rate versus rhythm control[31, 91]. Amiodarone may be a safe and effective option in clinical treatment for those with HCM with $\mathrm{AF}[15$, 65, 92]. The use of amiodarone was reported associated with fewer embolic episodes in a small study of 52 HCM patients with AF[93].

Catheter ablation (CA) may be another therapeutic choice in treating arrhythmia[49, 65]. But the effectiveness and safety of CA in HCM patients are controversial[ $[94,95]$. The success rate of a single
$\mathrm{CA}$ is lower in the HCM population due to AF recurrence, and patients in permanent AF had lower success rates than those in paroxysmal AF $(50 \%$ vs. $77 \%$, respectively)[96]. In general, left atrial dilation, mitral regurgitation, atrial fibrosis, and left outflow tract obstruction are also linked to lower success rates of CA[94, 97]. For the oral anticoagulant therapy after $\mathrm{CA}$, a recent study of AF subjects pointed that in 522 AF patients receiving $\mathrm{CA}$ and then remaining in sinus rhythm, warfarin was discontinued in $79 \%$ of 256 patients without risk factors and in $68 \%$ of 266 patients with $\geq 1$ risk factor. None of them had a thromboembolism event during $25 \pm 8$ months of follow-up, while patients older than 65 years or with a history of stroke were more likely to remain anticoagulated despite a successful outcome[98]. However, data on CA of AF in HCM patients are still sparse. Since highly recurrent AF after CA often required antiarrhythmic drugs or repeat ablation, continuing anticoagulation indefinitely in all patients after CA might be taken into account[39], and current guidelines also recommend life-long anticoagulation therapy even if the sinus rhythm is restored[49]. Generally, younger HCM patients with smaller atrial size, mild symptoms, and shorter duration of AF may have better clinical effects[99]. However, relevant data are still sparse. So whether younger HCM patients with paroxysmal AF who successfully managed by $\mathrm{CA}$ and maintained stable sinus rhythm should be treated lifelong with anticoagulation therapy needs further researches.

As for patients with obstructive HCM undergoing a surgical septal myectomy, a surgical Maze procedure can be an adjunctive operation for AF ablation, which has been proved to yield excellent hemodynamic benefits and may potentially decrease the risk of thromboembolic events[39, 100-102].

According to a prospective randomized study, in adult patients with hypertrophic obstructive cardiomyopathy who have severe mitral regurgitation, mitral valve plasty contributed to a lower rate of thromboembolic events[103].

\section{Conclusion}

On balance, the HCM population is at increased risk of potentially catastrophic thromboembolic events. Some risk factors on thromboembolism in $\mathrm{HCM}$, such as $\mathrm{AF}$, greater age, LAD, HF, and others have been confirmed. Since $\mathrm{CHADS}_{2}$ and $\mathrm{CHA}_{2} \mathrm{DS}_{2}-\mathrm{VASc}$ worked poorly in patients with HCM, several novel predictive models such as HCM Risk-CVA have been developed for risk stratification and validated to be more effective in HCM individuals than the conventional ones. Nevertheless, these new models lack external validations and there 
is no generally accepted model to predict thromboembolism in those suffering HCM. Currently, the most essential therapeutic measure is the lifelong anticoagulation treatment in all patients who have experienced even a single short of AF. Other managements such as regular monitor via ambulatory electrocardiogram for those without diagnosed $\mathrm{AF}$ and amiodarone or radiofrequency catheter ablation for HCM patients with AF were previously reported associated with less embolic events.

\section{Prospect}

In the HCM population, further data from large prospective studies regarding comprehensive thromboembolic risk factors, novel risk stratification models specialized for the HCM population with high sensitivity and specificity, and indications for prophylaxis, therapy, and prognosis are urgently needed.

\section{Abbreviations}

aCLa: anti-cardiolipin antibody; AF: atrial fibrillation; CA: catheter ablation; CMR: cardiovascular magnetic resonance; CVA: cerebrovascular accident; HCM: hypertrophic cardiomyopathy; HF: heart failure; INR: international normalized ratio; LAD: left atrial diameter; LGE: late gadolinium enhancement; LVOT: left ventricular outflow tract; MPV: mean platelet volume; MR: mitral regurgitation; MWT: maximal wall thickness; NOAC: new oral anticoagulant; NVAF: non-valvular atrial fibrillation; NYHA: New York Heart Association; SAM: systolic anterior movement; TE: thromboembolic event; TIA: transient ischaemic attacks; VKA: vitamin K antagonist.

\section{Acknowledgments}

We are thankful for the project from the National Eighth Five-Year Research Plan, China (grant no: 85-915-01-02), Mega-projects of Science Research for the 11th Five-Year Plan, China (grant no: 2006BAI01A01), and the National Natural Science Foundation of China (Grant number: 81600299).

\section{Author Contributions}

$\mathrm{Lu}$ Liu: analyzing data, interpreting results, drawing conclusion, and writing.

Zheng Liu: revising and writing a major revised manuscript.

Xiaoping Chen and Sen He: planning this study, offering suggestions, and submitting.

\section{Competing Interests}

The authors have declared that no competing interest exists.

\section{References}

1. Vaidya K, Semsarian C, Chan KH. Atrial Fibrillation in Hypertrophic Cardiomyopathy. Heart Lung Circ. 2017; 26: 975-82.

2. Critoph C, Elliott P. Hypertrophic Cardiomyopathy. Card Electrophysiol Clin. 2010; 2: 587-98.

3. Marian AJ, Braunwald E. Hypertrophic Cardiomyopathy: Genetics, Pathogenesis, Clinical Manifestations, Diagnosis, and Therapy. Circ Res. 2017; 121: 749-70.

4. Maron BJ, Nichols PF, 3rd, Pickle LW, Wesley YE, Mulvihill JJ. Patterns of inheritance in hypertrophic cardiomyopathy: assessment by M-mode and two-dimensional echocardiography. Am J Cardiol. 1984; 53: 1087-94.

5. Maron BJ. Hypertrophic cardiomyopathy. The Lancet. 1997; 350: 127-33.

6. Maron BJ. Hypertrophic cardiomyopathy: a systematic review. Jama. 2002; 287: 1308-20.

7. Franz W-M, Müller OJ, Katus HA. Cardiomyopathies: from genetics to the prospect of treatment. The Lancet. 2001; 358: 1627-37.

8. Fujita T, Fujino N, Anan R, Tei C, Kubo T, Doi Y, et al. Sarcomere gene mutations are associated with increased cardiovascular events in left ventricular hypertrophy: results from multicenter registration in Japan. JACC Heart Fail. 2013; 1: 459-66.

9. Alcalai R, Seidman JG, Seidman CE. Genetic basis of hypertrophic cardiomyopathy: from bench to the clinics. J Cardiovasc Electrophysiol. 2008; 19: $104-10$

10. Seidman CE, Seidman JG. Identifying sarcomere gene mutations in hypertrophic cardiomyopathy: a personal history. Circ Res. 2011; 108: 743-50.

11. Kumar KR, Mandleywala SN, Link MS. Atrial and ventricular arrhythmias in hypertrophic cardiomyopathy. Card Electrophysiol Clin. 2015; 7: 173-86.

12. Guttmann OP. Atrial fibrillation and thromboembolism in hypertrophic cardiomyopathy - An underestimated risk. Int J Cardiol. 2018; 273: 187-8.

13. Guttmann OP, Rahman MS, O'Mahony C, Anastasakis A, Elliott PM. Atrial fibrillation and thromboembolism in patients with hypertrophic cardiomyopathy: systematic review. Heart. 2014; 100: 465-72.

14. Maron BJ, Gardin JM, Flack JM, Gidding SS, Kurosaki TT, Bild DE. Prevalence of hypertrophic cardiomyopathy in a general population of young adults. Echocardiographic analysis of 4111 subjects in the CARDIA Study. Coronary Artery Risk Development in (Young) Adults. Circulation. 1995; 92: 785-9.

15. Patten M, Pecha S, Aydin A. Atrial Fibrillation in Hypertrophic Cardiomyopathy: Diagnosis and Considerations for Management. J Atr Fibrillation. 2018; 10: 1556.

16. Furlan AJ, Craciun AR, Raju NR, Hart N. Cerebrovascular complications associated with idiopathic hypertrophic subaortic stenosis. Stroke. 1984; 15: $282-4$

17. Russell JW, Biller J, Hajduczok ZD, Jones MP, Kerber RE, Adams HP, Jr. Ischemic cerebrovascular complications and risk factors in idiopathic hypertrophic subaortic stenosis. Stroke. 1991; 22: 1143-7.

18. Shigematsu Y, Hamada M, Mukai M, Matsuoka H, Sumimoto T, Hiwada K. Mechanism of atrial fibrillation and increased incidence of thromboembolism in patients with hypertrophic cardiomyopathy. Jpn Circ J. 1995; 59: 329-36.

19. Higashikawa M, Nakamura Y, Yoshida M, Kinoshita M. Incidence of ischemic strokes in hypertrophic cardiomyopathy is markedly increased if complicated by atrial fibrillation. Jpn Circ J. 1997; 61: 673-81.

20. Maron BJ, Olivotto I, Bellone P, Conte MR, Cecchi F, Flygenring BP, et al. Clinical profile of stroke in 900 patients with hypertrophic cardiomyopathy. J Am Coll Cardiol. 2002; 39: 301-7.

21. Veselka J. Hypertrophic Cardiomyopathy Is at Increased Risk of Thromboembolic Events: Deficiencies of CHA2DS2-VASC Score and How to Predict. Can J Cardiol. 2019: 35: 1629-30.

22. Haruki S, Minami Y, Hagiwara N. Stroke and Embolic Events in Hypertrophic Cardiomyopathy: Risk Stratification in Patients Without Atrial Fibrillation. Stroke. 2016; 47: 936-42.

23. Balsam P, Gawalko M, Peller M, Tyminska A, Ozieranski K, Zaleska M, et al. Clinical characteristics and thromboembolic risk of atrial fibrillation patients with and without congestive heart failure. Results from the CRATF study. Medicine (Baltimore). 2018; 97: e13074.

24. Choi YJ, Choi EK, Han KD, Jung JH, Park J, Lee E, et al. Temporal trends of the prevalence and incidence of atrial fibrillation and stroke among Asian patients with hypertrophic cardiomyopathy: A nationwide population-based study. Int J Cardiol. 2018; 273: 130-5.

25. Hirota T, Kubo T, Baba Y, Ochi Y, Takahashi A, Yamasaki N, et al. Clinical Profile of Thromboembolic Events in Patients With Hypertrophic Cardiomyopathy in a Regional Japanese Cohort- Results From Kochi RYOMA Study. Circ J. 2019; 83: 1747-54.

26. Guttmann OP, Pavlou M, O'Mahony C, Monserrat L, Anastasakis A, Rapezzi $\mathrm{C}$, et al. Prediction of thrombo-embolic risk in patients with hypertrophic cardiomyopathy (HCM Risk-CVA). Eur J Heart Fail. 2015; 17: 837-45.

27. Lorenzini M, Anastasiou Z, O'Mahony C, Guttman OP, Gimeno JR, Monserrat $\mathrm{L}$, et al. Mortality Among Referral Patients With Hypertrophic Cardiomyopathy vs the General European Population. JAMA Cardiol. 2020; 5 : 73-80.

28. Philipson DJ, Rader F, Siegel RJ. Risk factors for atrial fibrillation in hypertrophic cardiomyopathy. Eur J Prev Cardiol. 2019: 2047487319828474.

29. Lee SE, Park JK, Uhm JS, Kim JY, Pak HN, Lee MH, et al. Impact of atrial fibrillation on the clinical course of apical hypertrophic cardiomyopathy. Heart. 2017; 103: 1496-501. 
30. Maron BJ, Casey SA, Poliac LC, Gohman TE, Almquist AK, Aeppli DM. Clinical course of hypertrophic cardiomyopathy in a regional United States cohort. Jama. 1999; 281: 650-5

31. Siontis KC, Geske JB, Ong K, Nishimura RA, Ommen SR, Gersh BJ. Atrial fibrillation in hypertrophic cardiomyopathy: prevalence, clinical correlations, and mortality in a large high-risk population. J Am Heart Assoc. 2014; 3: e001002.

32. Okumura T, Kimura Y, Murohara T. Prediction of Thromboembolism in Patients With Hypertrophic Cardiomyopathy. Circ J. 2020; 84: 700-1.

33. Olivotto I, Cecchi F, Casey SA, Dolara A, Traverse JH, Maron BJ. Impact of atrial fibrillation on the clinical course of hypertrophic cardiomyopathy. Circulation. 2001; 104: 2517-24.

34. Borer JS, Atar D, Marciniak T, Kim MH, Serebruany V. Atrial Fibrillation and Stroke in Patients with Hypertrophic Cardiomyopathy: Important New Insights. Thromb Haemost. 2019; 119: 355-7.

35. Losi MA, Betocchi S, Aversa M, Lombardi R, Miranda M, D'Alessandro G, et al. Determinants of atrial fibrillation development in patients with hypertrophic cardiomyopathy. Am J Cardiol. 2004; 94: 895-900.

36. Tian T, Wang Y, Sun K, Wang J, Zou Y, Zhang W, et al. Clinical profile and prognostic significance of atrial fibrillation in hypertrophic cardiomyopathy. Cardiology. 2013; 126: 258-64

37. Jung H, Yang PS, Sung JH, Jang E, Yu HT, Kim TH, et al. Hypertrophic Cardiomyopathy in Patients with Atrial Fibrillation: Prevalence and Associated Stroke Risks in a Nationwide Cohort Study. Thromb Haemost. 2019; 119: 285-93.

38. Wolf PA, Abbott RD, Kannel WB. Atrial fibrillation as an independent risk factor for stroke: the Framingham Study. Stroke. 1991; 22: 983-8.

39. Rowin EJ, Hausvater A, Link MS, Abt P, Gionfriddo W, Wang W, et al. Clinical Profile and Consequences of Atrial Fibrillation in Hypertrophic Cardiomyopathy. Circulation. 2017; 136: 2420-36.

40. Ogimoto A, Hamada M, Nakura J, Miki T, Hiwada K. Relation between angiotensin-converting enzyme II genotype and atrial fibrillation in Japanese patients with hypertrophic cardiomyopathy. J Hum Genet. 2002; 47: 184-9.

41. Garg L, Gupta M, Sabzwari SRA, Agrawal S, Agarwal M, Nazir T, et al. Atrial fibrillation in hypertrophic cardiomyopathy: prevalence, clinical impact, and management. Heart Fail Rev. 2019; 24: 189-97.

42. Zegkos T, Efthimiadis GK, Parcharidou DG, Gossios TD, Giannakoulas G, Ntelios D, et al. Atrial fibrillation in hypertrophic cardiomyopathy: A turning point towards increased morbidity and mortality. Hellenic J Cardiol. 2017; 58: 331-9.

43. Kogure S, Yamamoto Y, Tomono S, Hasegawa A, Suzuki T, Murata K. High risk of systemic embolism in hypertrophic cardiomyopathy. Jpn Heart J. 1986; 27: 475-80.

44. Lin TT, Sung YL, Ko TY, Lee CK, Lin LY, Juang JJ, et al. Risk of ischemic stroke in patients with hypertrophic cardiomyopathy in the absence of atrial fibrillation - a nationwide cohort study. Aging (Albany NY). 2019; 11: 11347-57.

45. Ommen SR, Maron BJ, Olivotto I, Maron MS, Cecchi F, Betocchi S, et al. Long-term effects of surgical septal myectomy on survival in patients with obstructive hypertrophic cardiomyopathy. J Am Coll Cardiol. 2005; 46: 470-6.

46. Rastegar H, Boll G, Rowin EJ, Dolan N, Carroll C, Udelson JE, et al. Results of surgical septal myectomy for obstructive hypertrophic cardiomyopathy: the Tufts experience. Ann Cardiothorac Surg. 2017; 6: 353-63.

47. Hohneck A, Overhoff D, Doesch C, Sandberg R, Rudic B, Tueluemen E, et al. Extent of Late Gadolinium Enhancement Predicts Thromboembolic Events in Patients With Hypertrophic Cardiomyopathy. Circ J. 2020; 84: 754-62.

48. Benchimol Barbosa PR, Barbosa EC, Bomfim AS, Ribeiro RL, Boghossian SH, Kantharia BK. A practical score for risk stratification of embolic stroke in hypertrophic cardiomyopathy. European Heart Journal. 2013; 34: 531-

49. Elliott PM, Anastasakis A, Borger MA, Borggrefe M, Cecchi F, Charron P, et al. 2014 ESC Guidelines on diagnosis and management of hypertrophic cardiomyopathy: the Task Force for the Diagnosis and Management of Hypertrophic Cardiomyopathy of the European Society of Cardiology (ESC). Eur Heart J. 2014; 35: 2733-79.

50. Wang $\mathrm{Z}$, Liao $\mathrm{H}$, Chen $\mathrm{X}, \mathrm{He} \mathrm{S}$. Hyperuricemia: risk factor for thromboembolism in hypertrophic cardiomyopathy patients. Intern Emerg Med. 2020; 15: 1231-7.

51. He S, Wang Z, Cheem TH, Liao H, Chen X, He Y. External Validation of the Model of Thromboembolic Risk in Hypertrophic Cardiomyopathy Patients. Can J Cardiol. 2019; 35: 1800-6.

52. Camm AJ, Camm CF. Atrial Fibrillation and Anticoagulation in Hypertrophic Cardiomyopathy. Arrhythmia \& Electrophysiology Review. 2017; 6.

53. Gage BF, Waterman AD, Shannon W, Boechler M, Rich MW, Radford MJ. Validation of clinical classification schemes for predicting stroke: results from the National Registry of Atrial Fibrillation. Jama. 2001; 285: 2864-70.

54. Lip GY, Nieuwlaat R, Pisters R, Lane DA, Crijns HJ. Refining clinical risk stratification for predicting stroke and thromboembolism in atrial fibrillation using a novel risk factor-based approach: the euro heart survey on atrial fibrillation. Chest. 2010; 137: 263-72.

55. Camm AJ, Lip GY, De Caterina R, Savelieva I, Atar D, Hohnloser SH, et al. 2012 focused update of the ESC Guidelines for the management of atrial fibrillation: an update of the 2010 ESC Guidelines for the management of atrial fibrillation. Developed with the special contribution of the European Heart Rhythm Association. Eur Heart J. 2012; 33: 2719-47.
56. Camm AJ, Kirchhof P, Lip GY, Schotten U, Savelieva I, Ernst S, et al Guidelines for the management of atrial fibrillation: the Task Force for the Management of Atrial Fibrillation of the European Society of Cardiology (ESC). Europace. 2010; 12: 1360-420.

57. Guidelines for Diagnosis and Treatment of Patients With Hypertrophic Cardiomyopathy (JCS 2012) - Digest Version Circ J. 2016; 80: 753-74.

58. Weir RA, MacKenzie N, Petrie CI. Cheating the CHA2DS2-VASc Score: Thromboembolism in Apical Hypertrophic Cardiomyopathy. Case Rep Cardiol. 2014; 2014: 189895

59. Kirchhof P, Benussi S, Kotecha D, Ahlsson A, Atar D, Casadei B, et al. 2016 ESC Guidelines for the management of atrial fibrillation developed in collaboration with EACTS. Europace. 2016; 18: 1609-78.

60. Veselka J, Anavekar NS, Charron P. Hypertrophic obstructive cardiomyopathy. Lancet. 2017; 389: 1253-67.

61. Tsuda T, Hayashi K, Fujino N, Konno T, Tada H, Nomura A, et al. Effect of Hypertrophic Cardiomyopathy on Prediction of Thromboembolism in Patients with Non-valvular Atrial Fibrillation. Heart Rhythm. 2019; 16: 829-37.

62. Barra S, Almeida I, Caetano F, Providencia R, Paiva L, Dinis P, et al. Stroke prediction with an adjusted R-CHA2DS2VASc score in a cohort of patients with a Myocardial Infarction. Thromb Res. 2013; 132: 293-9.

63. Wang $\mathrm{Z}$, Liao $\mathrm{H}, \mathrm{He} \mathrm{S}$, Chen $\mathrm{X}$. Performance and validation of R-CHA2DS2VASc score for thromboembolism in patients with hypertrophic cardiomyopathy. Hellenic J Cardiol. 2019.

64. January CT, Wann LS, Alpert JS, Calkins H, Cigarroa JE, Cleveland JC, Jr., et al. 2014 AHA/ACC/HRS guideline for the management of patients with atrial fibrillation: executive summary: a report of the American College of Cardiology/American Heart Association Task Force on practice guidelines and the Heart Rhythm Society. Circulation. 2014; 130: 2071-104.

65. Gersh BJ, Maron BJ, Bonow RO, Dearani JA, Fifer MA, Link MS, et al. 2011 ACCF/AHA guideline for the diagnosis and treatment of hypertrophic cardiomyopathy: executive summary: a report of the American College of Cardiology Foundation/American Heart Association Task Force on Practice Guidelines. Circulation. 2011; 124: 2761-96.

66. Kamel H, Okin PM, Elkind MS, Iadecola C. Atrial Fibrillation and Mechanisms of Stroke: Time for a New Model. Stroke. 2016; 47: 895-900.

67. Maron BJ, Rowin EJ, Casey SA, Haas TS, Chan RH, Udelson JE, et al. Risk stratification and outcome of patients with hypertrophic cardiomyopathy $>=60$ years of age. Circulation. 2013; 127: 585-93.

68. Oh S, Goto S, Accetta G, Angchaisuksiri P, Camm AJ, Cools F, et al. Vitamin K antagonist control in patients with atrial fibrillation in Asia compared with other regions of the world: Real-world data from the GARFIELD-AF registry. Int J Cardiol. 2016; 223: 543-7.

69. Cowan C, Healicon R, Robson I, Long WR, Barrett J, Fay M, et al. The use of anticoagulants in the management of atrial fibrillation among general practices in England. Heart. 2013; 99: 1166-72.

70. Zhou Y, He W, Zhou Y, Zhu W. Non-vitamin K antagonist oral anticoagulants in patients with hypertrophic cardiomyopathy and atrial fibrillation: a systematic review and meta-analysis. J Thromb Thrombolysis. 2020; 50: 311-7.

71. Gersh BJ, Maron BJ, Bonow RO, Dearani JA, Fifer MA, Link MS, et al. 2011 ACCF/AHA guideline for the diagnosis and treatment of hypertrophic cardiomyopathy: a report of the American College of Cardiology Foundation/American Heart Association Task Force on Practice Guidelines. J Thorac Cardiovasc Surg. 2011; 142: e153-203.

72. Lozier MR, Sanchez AM, Lee JJ, Donath EM, Font VE, Escolar E. Thromboembolic Outcomes of Different Anticoagulation Strategies for Patients with Atrial Fibrillation in the Setting of Hypertrophic Cardiomyopathy: A Systematic Review. J Atr Fibrillation. 2019; 12: 2207.

73. Jung H, Yang PS, Jang E, Yu HT, Kim TH, Uhm JS, et al. Effectiveness and Safety of Non-Vitamin K Antagonist Oral Anticoagulants in Patients With Atrial Fibrillation With Hypertrophic Cardiomyopathy: A Nationwide Cohort Study. Chest. 2019; 155: 354-63.

74. Lip GYH, Keshishian A, Li X, Hamilton M, Masseria C, Gupta K, et al. Effectiveness and Safety of Oral Anticoagulants Among Nonvalvular Atrial Fibrillation Patients. Stroke. 2018; 49: 2933-44.

75. Ntaios G, Papavasileiou V, Makaritsis K, Vemmos K, Michel P, Lip GYH. Real-World Setting Comparison of Nonvitamin-K Antagonist Oral Anticoagulants Versus Vitamin-K Antagonists for Stroke Prevention in Atrial Fibrillation: A Systematic Review and Meta-Analysis. Stroke. 2017; 48: 2494-503.

76. Creta A, Hunter RJ, Earley MJ, Finlay M, Dhinoja M, Sporton S, et al. Non-vitamin $\mathrm{K}$ oral anticoagulants in hypertrophic cardiomyopathy patients undergoing catheter ablation of atrial fibrillation. J Cardiovasc Electrophysiol. 2020.

77. Maron BJ, Maron MS. Hypertrophic cardiomyopathy. The Lancet. 2013; 381: 242-55.

78. Dimitrow PP, Undas A, Bober M, Tracz W, Dubiel JS Obstructive hypertrophic cardiomyopathy is associated with enhanced thrombin generation and platelet activation. Heart. 2008; 94: e21.

79. Cambronero F, Marin F, Roldan V, Hernandez-Romero D, Valdes M, Lip GY. Biomarkers of pathophysiology in hypertrophic cardiomyopathy: implications for clinical management and prognosis. Eur Heart J. 2009; 30: 139-51.

80. Icli A, Aksoy F, Dogan A, Arslan A, Akcay S, Yucel H, et al. Increased mean platelet volume in hypertrophic cardiomyopathy. Angiology. 2014; 65: 420-4. 
81. van Walraven C, Hart RG, Singer DE, Laupacis A, Connolly S, Petersen P, et al. Oral anticoagulants vs aspirin in nonvalvular atrial fibrillation: an individual patient meta-analysis. Jama. 2002; 288: 2441-8.

82. Sato H, Ishikawa K, Kitabatake A, Ogawa S, Maruyama Y, Yokota Y, et al. Low-dose aspirin for prevention of stroke in low-risk patients with atrial fibrillation: Japan Atrial Fibrillation Stroke Trial. Stroke. 2006; 37: 447-51.

83. Lip GY, Lim HS. Atrial fibrillation and stroke prevention. Lancet Neurol. 2007; 6: $981-93$.

84. Mant J, Hobbs FD, Fletcher K, Roalfe A, Fitzmaurice D, Lip GY, et al. Warfarin versus aspirin for stroke prevention in an elderly community population with atrial fibrillation (the Birmingham Atrial Fibrillation Treatment of the Aged Study, BAFTA): a randomised controlled trial. Lancet. 2007; 370: 493-503.

85. Flaker GC, Belew K, Beckman K, Vidaillet H, Kron J, Safford R, et al. Asymptomatic atrial fibrillation: demographic features and prognostic information from the Atrial Fibrillation Follow-up Investigation of Rhythm Management (AFFIRM) study. Am Heart J. 2005; 149: 657-63.

86. Ritter MA, Kochhäuser S, Duning $T$, Reinke F, Pott $C$, Dechering DG, et al. Occult atrial fibrillation in cryptogenic stroke: detection by 7-day electrocardiogram versus implantable cardiac monitors. Stroke. 2013; 44: 1449-52.

87. Sanna T, Diener HC, Passman RS, Di Lazzaro V, Bernstein RA, Morillo CA, et al. Cryptogenic stroke and underlying atrial fibrillation. N Engl J Med. 2014; 370: $2478-86$.

88. Favilla CG, Ingala E, Jara J, Fessler E, Cucchiara B, Messé SR, et al. Predictors of finding occult atrial fibrillation after cryptogenic stroke. Stroke. 2015; 46: 1210-5.

89. Wilke I, Witzel K, Münch J, Pecha S, Blankenberg S, Reichenspurner H, et al. High Incidence of De Novo and Subclinical Atrial Fibrillation in Patients With Hypertrophic Cardiomyopathy and Cardiac Rhythm Management Device. J Cardiovasc Electrophysiol. 2016; 27: 779-84.

90. Rowin EJ, Orfanos A, Estes NAM, Wang W, Link MS, Maron MS, et al, Occurrence and Natural History of Clinically Silent Episodes of Atrial Fibrillation in Hypertrophic Cardiomyopathy. Am J Cardiol. 2017; 119: 1862-5.

91. Kubo T, Kitaoka H, Okawa M, Hirota T, Hayato K, Yamasaki N, et al. Clinical impact of atrial fibrillation in patients with hypertrophic cardiomyopathy. Results from Kochi RYOMA Study. Circ J. 2009; 73: 1599-605.

92. Spoladore R, Maron MS, D'Amato R, Camici PG, Olivotto I. Pharmacological treatment options for hypertrophic cardiomyopathy: high time for evidence. Eur Heart J. 2012; 33: 1724-33.

93. Robinson K, Frenneaux MP, Stockins B, Karatasakis G, Poloniecki JD, McKenna WJ. Atrial fibrillation in hypertrophic cardiomyopathy: a longitudinal study. J Am Coll Cardiol. 1990; 15: 1279-85.

94. Providencia R, Elliott P, Patel K, McCready J, Babu G, Srinivasan N, et al. Catheter ablation for atrial fibrillation in hypertrophic cardiomyopathy: a systematic review and meta-analysis. Heart. 2016; 102: 1533-43.

95. Zhao DS, Shen Y, Zhang Q, Lin G, Lu YH, Chen BT, et al. Outcomes of catheter ablation of atrial fibrillation in patients with hypertrophic cardiomyopathy: a systematic review and meta-analysis. Europace. 2016; 18: 508-20.

96. Gaita F, Di Donna P, Olivotto I, Scaglione M, Ferrero I, Montefusco A, et al. Usefulness and safety of transcatheter ablation of atrial fibrillation in patients with hypertrophic cardiomyopathy. Am J Cardiol. 2007; 99: 1575-81.

97. Contreras-Valdes FM, Buxton AE, Josephson ME, Anter E. Atrial fibrillation ablation in patients with hypertrophic cardiomyopathy: long-term outcomes and clinical predictors. J Am Coll Cardiol. 2015; 65: 1485-7.

98. Oral H, Chugh A, Ozaydin M, Good E, Fortino J, Sankaran S, et al. Risk of thromboembolic events after percutaneous left atrial radiofrequency ablation of atrial fibrillation. Circulation. 2006; 114: 759-65.

99. Di Donna P, Olivotto I, Delcre SD, Caponi D, Scaglione M, Nault I, et al. Efficacy of catheter ablation for atrial fibrillation in hypertrophic cardiomyopathy: impact of age, atrial remodelling, and disease progression. Europace. 2010; 12: 347-55.

100. MacIntyre C, Lakdawala NK. Management of Atrial Fibrillation in Hypertrophic Cardiomyopathy. Circulation. 2016; 133: 1901-5.

101. Chen MS, McCarthy PM, Lever HM, Smedira NG, Lytle BL. Effectiveness of atrial fibrillation surgery in patients with hypertrophic cardiomyopathy. Am J Cardiol. 2004; 93: 373-5.

102. Quintana E, Cox JL. Surgical management of atrial fibrillation at the time of septal myectomy. Ann Cardiothorac Surg. 2017; 6: 386-93.

103. Bogachev-Prokophiev A, Afanasyev A, Zheleznev S, Fomenko M, Sharifulin $\mathrm{R}$, Kretov E, et al. Mitral valve repair or replacement in hypertrophic obstructive cardiomyopathy: a prospective randomized study. Interact Cardiovasc Thorac Surg. 2017; 25: 356-62. 